\title{
Influence of sowing methods on biometric indicators of domestic and international rice varieties
}

\author{
$R$. Tellyaev ${ }^{1, *}, M$. Ergashev $^{2}, B . \mathrm{Kodirov}^{3}$, and $A . \mathrm{Kholboev}^{3}$ \\ ${ }^{1}$ Tashkent State Agrarian University, University str., 2, Tashkent province, Uzbekistan, 100140 \\ ${ }^{2}$ Scientific Research Institute of Grain and Legumes, Andijan str., 36, Kuygan-Yor hamlet, Andijan \\ province, Uzbekistan \\ ${ }^{3}$ Scientific Research Institute of Rice Culture, Ok-Ota rural administration, Urtachirchik district, \\ Tashkent province, Uzbekistan
}

\begin{abstract}
This article presents the results of a study on the introduction of South Korean rice varieties, the influence of transplanting methods on the biometric indicators of local and foreign varieties, as well as the selection of varieties adapted for transplanting method using mechanization.
\end{abstract}

\section{Introduction}

Agriculture in Uzbekistan is a diversified sector, in which, along with many other agricultural crops, rice has long been grown as a source of rice, one of the staple foods of the population. Rice is one of the most important types of food for human beings, it is rich in protein and vitamins, and it is a natural delicacy that people love and eat, especially the holiday and wedding table of the peoples of Central Asia [1].

The concept for the Efficient Use of Land and Water Resources in Agriculture, developed in accordance with Presidential Decrees No. 3281 and No. 5742, also states that over the past 15 years, the population has grown over the past 15 years due to rapid population growth, diversification of agricultural lands and the effects of global climate change. The volume of irrigated land per capita decreased by $24 \%$ (from 0.23 hectares to 0.16 hectares), and the average annual water supply decreased from 3,048 cubic meters to 158.9 cubic meters. "The level of water supply is declining from year to year $[2,3]$.

This is evidenced by the fact that the Government attaches great importance to rice cultivation in the "Program of measures to expand the area under rice in the coming years in the Republic of Karakalpakstan and its regions, gradually increase yields and production volumes, approved by the Prime Minister of the Republic of Uzbekistan [1].

In Uzbekistan, rice is grown mainly as a primary and secondary crop in the Republic of Karakalpakstan, Khorezm, Tashkent, Syrdarya, Surkhandarya, Fergana, Andijan, and Namangan provinces on an area of about 114,000 hectares. The average yield is 35-38 quintals per hectare, and the gross yield is 421,000 tons. This amount meets the growing demand of the country's population for basic foodstuffs in regards of rice. According to

\footnotetext{
* Corresponding author: r.tellyayev@yandex.com
} 
official data, about 35,000 tons of rice products are imported annually to fully meet the needs of the population $[1,6]$.

In order to obtain high yields of rice in the country, to meet the demand of the population for rice products and to reduce the amount of imports, to save currency, to place high-yielding rice varieties resistant to local soil and climatic conditions, to develop highefficiency resource-saving agro-technologies are the most recent and important tasks $[4,5]$. It should be noted that the productivity of Uzbek rice remains much lower than that of world rice. There are many specific objective and subjective reasons for this, one of which is the lack of use of innovative, resource-saving technologies that are widely used in the practice of world rice [8].

Cultivation of rice by seedling method is one of the most important progressive branches of this technological process, which has a number of advantages and disadvantages over the traditional method of cultivation from seed. This method is the main contender for the full implementation of the main road planting method, as in all countries of the world, where the rice industry of Uzbekistan grows other rice [9].

Because in Uzbekistan there are natural and scientific opportunities for the cultivation of rice, the basis of which are saline lands and waters, where it is impossible to grow other agricultural crops. Due to rapid population growth, global climate change, the Aral Sea and the Aral Sea crisis, rising average annual temperatures, frequent droughts, declining river water levels, increasing salinity, it is becoming increasingly difficult to grow abundant and high-quality rice. The shortage of local rice varieties resistant to these conditions, the lack of research on foreign varieties, further complicates the solution of the problem $[9,12]$.

One of the most important directions in the effective solution of this problem is the cultivation of rice by seedling method, which accounts for $80-90 \%$ of world practice. Taking into account soil and climatic conditions and biological characteristics of varieties, improving the agro-techniques of rice cultivation, increasing productivity, introduction of advanced technologies in the world and efficient use of each hectare is one of the most pressing issues of rice farming in the country. Given the limited land and water resources, increasing the efficiency of rice cultivation and making full use of the biological properties of promising local varieties and grow seedlings twice a year in an innovative way is important $[10,11]$.

Today, one of the most important tasks is to further increase the yield of cereals, including rice, to meet the food needs of the world's population. This is due to the fact that in world agriculture there is a steady increase in rice yields $(90-100 \mathrm{q} / \mathrm{ha})$. During the coronavirus pandemic in the world food market, rice became a new "black gold". A sharp rise in demand and a decline in exports are pushing up rice prices too much [10,13].

In recent years, the world's agriculture has been conducting intensive research on the application of new innovative resource-saving technologies on a scientific basis to increase the yield of rice, to harvest two or three times a year. In this regard, the study and improvement of existing technologies for the cultivation of ecologically clean, abundant and high-quality products from rice, special attention to a clear agricultural system is also important in the context of the republic. Efficient use of vacant lands of autumn cereals and other early crops, rational timing, scheme and number of seedlings of rice varieties, optimization of agro-technical elements of cultivation are important theoretical and practical tasks $[1,5]$.

As a result of the development of technology by Chinese scientists to prepare rice seedlings in special nurseries, rice is harvested twice a year. At the same time, scientists sowed the seeds of early and middle-ripe varieties of rice in special nurseries in the second decade of March, when the seedlings were 25-30 days old, i.e. in the second decade of April, transplanted to the main field and harvested in the first decade of July. Rice seedlings 
prepared in a special nursery were planted in the main field in the second decade of July as a second crop and harvested in late October [11].

World rice growers, based on many years of experience, have sharply shifted the method of planting from seed to the method of sowing seeds, given its many advantages and benefits, and part of the burden and concern of this method has been placed on mechanization. As a result, various devices, planting mechanisms have been created and tested in practice in many countries. As a result, an innovative method, i.e. the technology of mechanized planting and cultivation of rice by seedling method, has been created and is effectively used in $90-95 \%$ of rice fields in the world $[8,11]$.

Uzbekistan also has its own long-term rice school; all cultivated varieties are local varieties and have achieved good results in terms of yield, especially grain quality. The main task of modern rice in Uzbekistan is to study the high-yielding varieties, hybrids and intensive technologies of advanced countries in the local context, the introduction, introduction and equalization of techniques. At the same time, along with the re-creation and improvement of agrotechnology for the cultivation of high-yielding and early-maturing varieties and hybrids of rice in different soil-climatic conditions in a clear farming system, special attention should be paid to their productivity and quality $[8,9,12]$.

According to R. Tellyaev [1], rice cultivation can save an average of 5-6 thousand cubic meters of water compared to the traditional method, and seed consumption is 3-4 times lower. The author also emphasizes that the quality of the product produced by the method of planting rice as a secondary crop in the seedling method is higher than that grown by the conventional method.

According to R. Tellyaev [6] and E. Jumanov [8], when the early ripening rice seedlings "Guljakhon" were prepared in special nurseries and planted by mechanical means, the salinity of the soil with sodium chloride 0.02 up to $3.0 \%$ with sodium sulphate, and Apus concriformis Sh, a shielding shrimp that causes severe damage during the germination phase when sown from seed. All created parasites are varieties, and the creation of hybrids is not yet on the agenda. This method is also a reserve to increase yields by $10-20 \%$ in the future.

Therefore, the main purpose of the study is to increase the efficiency of rice, full use of biological properties of promising local varieties, localization of foreign rice varieties and hybrids, innovative methods of seedling preparation and further improvement of agrotechnological elements and mechanized planting of rice seedlings.

\section{Materials and methods}

\subsection{Study area}

Scientific Research Institute of Rice Culture is located in the south-eastern part of the Tashkent province, in the Chirchik oasis, $15 \mathrm{~km}$ from Tashkent, on the left bank of the Chirchik River. Geographically, its coordinates are bounded on the Greenwich scale by $69^{\circ} 18^{\prime}$ east longitude and $41^{\circ} 20^{\prime}$ north latitude (Figure 1). 


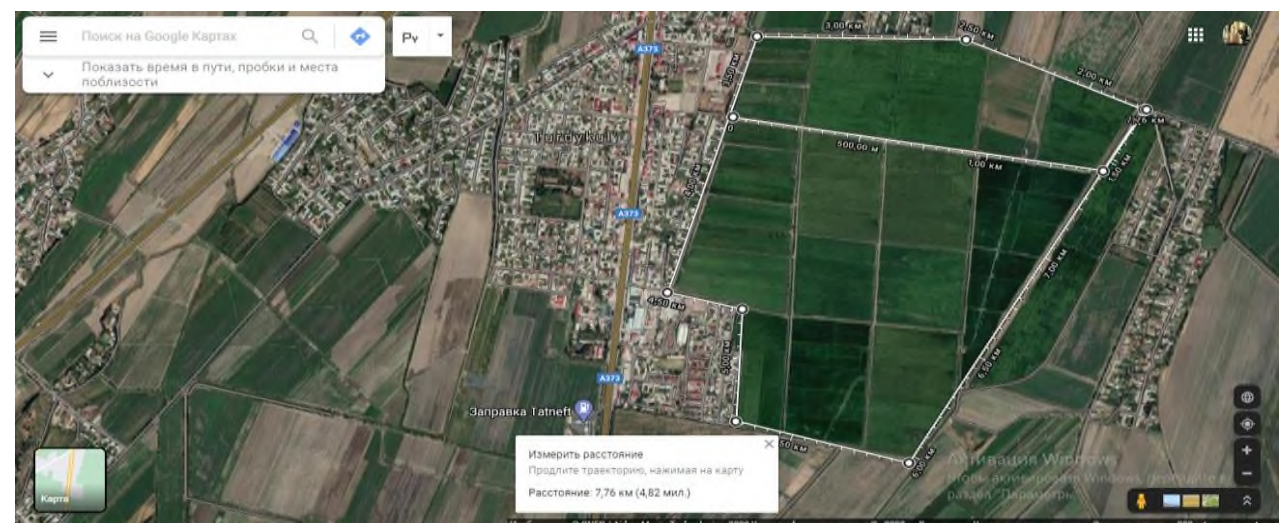

Fig. 1. Satellite image of the study area

The topography of the area is flat, the soil in the experimental fields corresponds to the soil of the riverine areas, and the soil layer of the area consists of gray meadows and meadow swampy soils.

The driving layer is $0-30$ and $0-40 \mathrm{~cm}$, below the driving layer there is a layer of gel 30 $40 \mathrm{~cm}$ thick, at a depth of $60-70 \mathrm{~cm}$ there is a layer of sand and small stones. The sandy and fine-grained layer is also found in some parts of the experimental area in the $30-40 \mathrm{~cm}$ layer (Table 1).

Table 1. Determination of total humus and mobile nitrogen, phosphorus, potassium and water-soluble salts in soil samples, 2020

\begin{tabular}{|c|c|c|c|c|c|c|c|c|}
\hline \multirow[b]{2}{*}{ \# } & \multirow{2}{*}{ 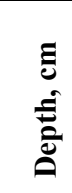 } & \multirow{2}{*}{ 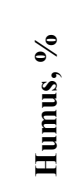 } & \multirow[b]{2}{*}{ 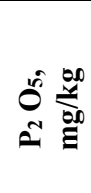 } & \multirow{2}{*}{ 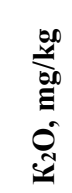 } & \multirow[b]{2}{*}{ 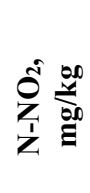 } & \multicolumn{2}{|c|}{ Soil salinity } & \multirow[b]{2}{*}{ pH } \\
\hline & & & & & & Type & Degree & \\
\hline 1 & $0-30$ & 1.92 & 17.6 & 108 & 20.7 & Chloro-sulphur & Weak & 7.08 \\
\hline 2 & $0-30$ & 2.32 & 14.4 & 106 & 22.9 & Sulphur & No salinity & 7.19 \\
\hline 3 & $0-30$ & 2.35 & 9.6 & 106 & 21.6 & Chloro-sulphur & Weak & 7.30 \\
\hline 4 & $0-30$ & 2.12 & 7.04 & 115 & 20.4 & Sulphur & No salinity & 7.39 \\
\hline 5 & $0-30$ & 2.16 & 11.2 & 96 & 25.6 & Sulphur & No salinity & 7.22 \\
\hline
\end{tabular}

The soils of the experimental farm of the Institute are mostly unsalted, the reaction is neutral (RN-7.08 - 7.39), the mechanical composition is heavy sand. The content of humus is $2.53 \%$, nitrogen $15.6 \mathrm{mg} / \mathrm{kg}$, phosphorus $14.4 \mathrm{mg} / \mathrm{kg}$, potassium $120 \mathrm{mg} / \mathrm{kg}$.

The experimental area was found to be partially sloping, the lower layer of soil was composed of sand and pebbles, and groundwater flowed from the north-east to the southwest.

According to data from the Tuyabogiz meteorological station in 2020, the average air temperature during the growing season of the plant was $+25.9^{\circ} \mathrm{C}$ degrees over the years. The highest air temperature was observed in July and amounted to $+35.4^{\circ} \mathrm{C}$ degrees. In some years, the minimum air temperature can drop to 10-15 degrees. However, in some 
years the winter comes cold. Daily air temperatures can be as high as 0 degrees in February [7].

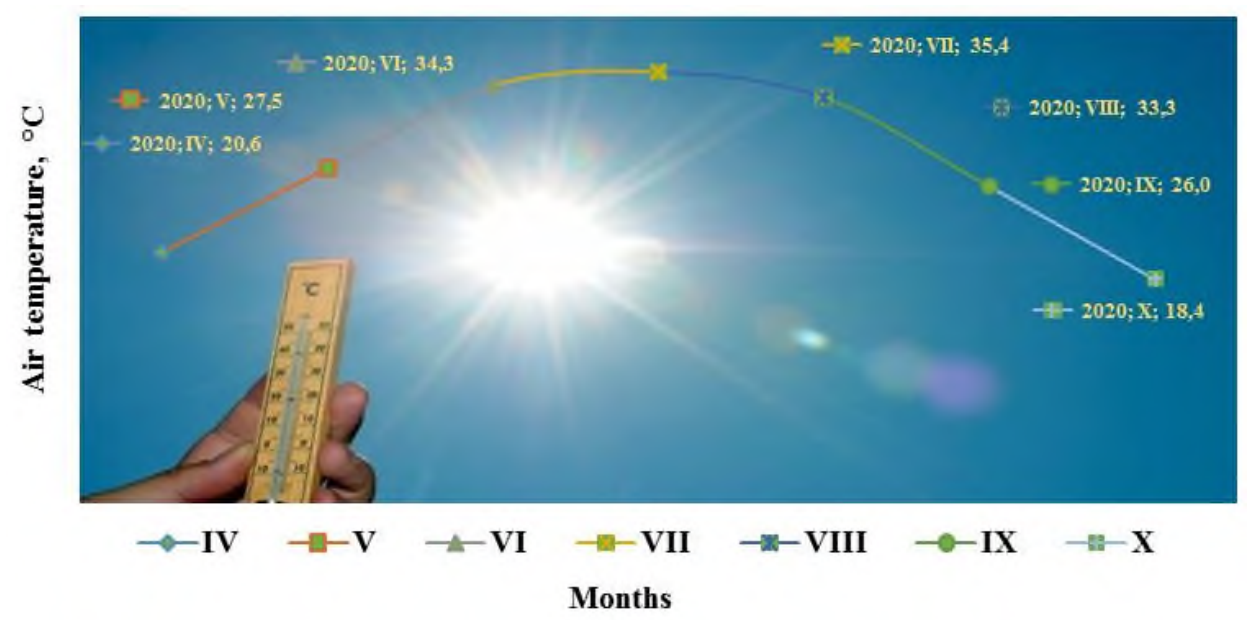

Fig. 2. Annual air temperature of the study area

\subsection{Methodology}

\subsubsection{Determination of organic matter of soil by Tyurin method}

Theoretical basis of the work: the method recommended by academician IV Tyurin is a volumetric method, which is easy and convenient to perform in the laboratory [6]. This method is based on the oxidation of carbon (C) in humus in a solution of chromic anhydride and the titration of excess chromic anhydride with Mor salt:

$$
\begin{gathered}
3 \mathrm{C}+2 \mathrm{~K}_{2} \mathrm{Cr}_{2} \mathrm{O}_{7}+8 \mathrm{H}_{2} \mathrm{SO}_{4}= \\
\left.\mathrm{Cr}\left(\mathrm{SO}_{4}\right)_{3}+3 \mathrm{SO}_{4}\right)_{3}+2 \mathrm{KO}_{4} \mathrm{SO}_{4}+8 \mathrm{H}_{2} \mathrm{O}+3 \mathrm{~K}_{2} \mathrm{SO}_{4}+7 \mathrm{CO}_{2} \mathrm{~K}_{2} \mathrm{Cr} \mathrm{Cr}_{2} \mathrm{O}_{7}+7 \mathrm{H}_{2} \mathrm{SO}_{4}+6 \mathrm{FeSO}_{4}=
\end{gathered}
$$

The order of work in the laboratory was as follows: 0.1-0.5 g of humus was weighed from the soil prepared for analysis on an analytical balance, depending on the approximate amount of humus. The less humus, the more the sample is taken and vice versa. The sample is carefully poured into a $100 \mathrm{ml}$ conical flask so that soil particles do not remain on the walls of the flask. Then pour $10 \mathrm{ml}$ of $0.4 \mathrm{~N}$ chromate anhydride solutions using a burette, shake well and close its mouth with a small glass funnel or special coolers. In 1967, B.A. Nikitin proposed to heat the boil for 30 minutes in a special drying oven at 1,500 degrees [1]. But it was later accepted by Simakova that heating for 20 minutes at 1200 was sufficient for the soils in the processed variant [12]. After the allotted time, the tubes are removed from the thermostat and cooled. After the tube has cooled, 30-50 ml of distilled water is poured over it and 3-4 drops of phenylanthranyl or defenilamine solution as an indicator are added and slowly mixed with a glass rod. When the solution in the flask turns dark blue, titrate with $0.2 \mathrm{n}$ Mor salt until it turns pale green.

\subsubsection{Determination of the total amount of NPK in the soil}

The ammonium and nitrate forms of nitrogen in the soil are dynamic in nature and are directly related to microbiological activity. Information on the nitrogen regime can be 
obtained only by re-determining them several times during the growing season. Data on the nitrogen supply of soils can be obtained from readily hydrolyzed nitrogen indicators in the soil organic matter composition. Nitrites, on the other hand, are so low in the soil that their effects on the plant have not been fully disclosed, and there are even speculations that they may have a negative effect.

The most convenient way of colorimetric determination of nitrogen is the Nessler method [8]. The essence of this method is that ammonium ions react with potassium mercury to form water-insoluble mercuric iodine:

$$
\mathrm{NH}_{4} \mathrm{OH}+2 \mathrm{~K}_{2} \mathrm{HgI}_{4}+3 \mathrm{KOH}=\left[\mathrm{NH}_{2} \mathrm{Hg}_{2} \mathrm{OI}\right]+7 \mathrm{I}+3 \mathrm{H}_{2} \mathrm{O}
$$

The main component of Nessler's reagent is mercury iodine, which forms a stable compound in an alkaline environment. Therefore, this reaction can only be carried out in a neutral or alkaline environment. Since the color of the solution depends on the size of the colloidal particles, special attention should be paid to the order of injection of the reagents. It should be noted that the determination of nitrogen can be hampered by sediments that form cations in an alkaline environment.

The amount of phosphorus in the soils of Central Asia varies from 0.08 to 0.3 . The distribution of phosphorus according to certain regularity in the soil profile has not been observed and depends only on the amount in the parent rock. This method is based on the formation of a complex compound with phosphorus under the action of ammonium molybdenum. Molybdenum phosphate acid is converted to molybdenum oxides, which have an air color, under the action of potassium in an acidic environment.

\subsubsection{Determination of the total amount of NPK in the soil}

The mobile form of nitrogen in the soil was determined by the Granvald Lyaju method [10].The essence of this method is based on the order of precipitation of the liquid by exposure to disulfophenolic acid in an alkaline environment:

$$
\mathrm{C}_{6} \mathrm{H}_{3} \mathrm{OH}\left(\mathrm{HSO}_{3}\right)_{2}+3 \mathrm{HNO}_{3}=\mathrm{C}_{6} \mathrm{H}_{2} \mathrm{OH}\left(\mathrm{NO}_{2}\right)_{3}+2 \mathrm{H}_{2} \mathrm{SO}_{4}+\mathrm{H}_{2} \mathrm{O}
$$

Experiments, phenological observations and sampling of plants were carried out on the basis of "Methods of conducting field experiments" and "Guidelines for rice cultivation in Uzbekistan".

The research includes early-ripening varieties Guljakhon, middle-ripening Iskandar, late-ripening Lazurnyy, Tarona, Tantana and early-maturing varieties Sanam and South Korea, developed by scientists of the Institute of Rice Research and Karakalpakstan. Jinbu, Taebaek, Goami, Heokjinju, Dongjin and Chokwang varieties of rice were used.

\subsubsection{Process of growing seedlings}

The process of growing seedlings is carried out in the following stages:

Sorting the seeds in salted water. This method is based on the principle of leaking immature grains on the surface of the water due to the increase in water density. To do this, add 30 liters of water to a container with a capacity of 40 liters, slowly add salt and stir. Stir in the salt solution until the raw egg of the bird (chicken) floats on the surface of the water without sinking. Once the egg has risen to the surface of the water, the amount of salt is stopped, $10 \mathrm{~kg}$ of rice seeds are added to the saline solution and mixed slowly. Some of the rice seeds remain on the surface of the solution and the rest sinks to the bottom of the solution. The seeds that have leaked to the surface of the solution are removed and 
discarded. The seeds deposited at the bottom of the solution are taken in a separate container, rinsed twice in clean water, then spread and dried quickly. If the seeds are sown quickly, the seeds are treated in the next stage of technology.

Seed treatment. A solution is prepared by adding $10 \mathrm{~g}$ of Celest-Top (fungicide, insecticide, stimulant) to 10 liters of water, and the seeds are added and stored for 24 hours.

Seed germination and germination. The treated seeds are rinsed 2 times in clean water and soaked in clean water for two days. During the heating process, the water is changed daily. After two days, the seeds are removed from the water, rinsed thoroughly in warm water and placed in gray bags, wrapped for 48 hours and treated. From time to time warm water was sprinkled on the bags. During the same 48-hour bag wrapping seeds $1-1.5 \mathrm{~mm}$. an apostate appears.

The soil and manure are passed through a separate sieve with a diameter of 2-3 mm. Mix $10 \%$ manure, $10 \%$ sand and 3\% ammophos into the soil, add $2 \mathrm{~kg}$ to each cassette and spread evenly.

Sowing the seeds. To each cassette filled with soil mixture $200 \mathrm{~g}$ of sown seeds are sown and a 2-3 mm thick soil mixture is sprinkled on the sown seeds and sprinkled on top. The top of the cassettes is covered with polyethylene film. The seeds are placed on racks and placed in a greenhouse to ensure that they germinate evenly.

Seedling care. The sown seeds were transplanted to special nurseries as soon as they began to germinate on the soil surface after 48 hours. In order not to damage the sprouting plants, it was periodically irrigated with warm water. Under these conditions, the seeds germinated completely in 5 days, and the seedlings were watered twice a day for a week (Figure 3).
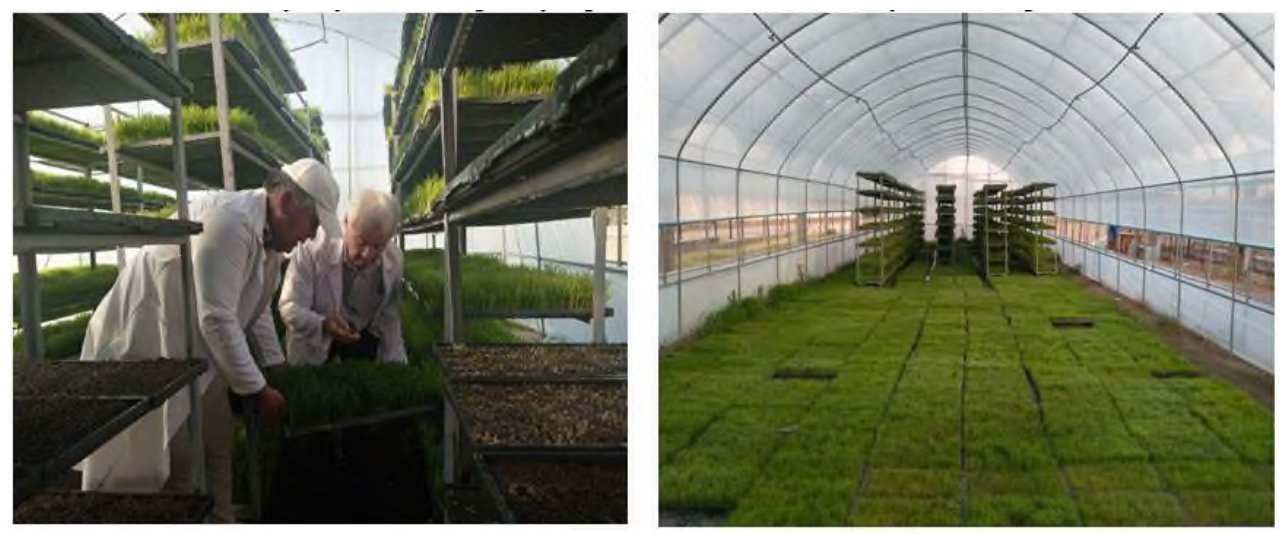

Fig. 3. Care of rice seedlings in special nurseries

After 25-30 days of rice seedlings, 4-5 seedlings were planted in each nest at a distance of 30-10 cm using a special (PRO600V) seedling machine imported from South Korea, which planted seedlings in the main field. The day the rice seedlings were taken out of the field. There are 5 million seeds per hectare of rice sown from seeds. The seeds are soaked in water for 1-2 days and sown side by side. The rest of the fieldwork was the same as the control option (Figure 4). 

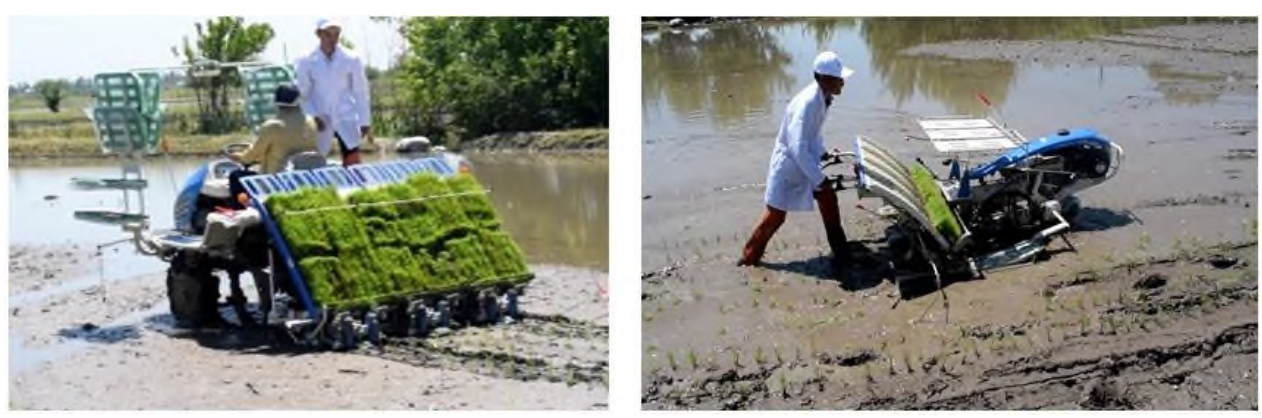

Fig. 4. Planting rice seedlings using seedling sowing machines

$5 \%$ of the annual nitrogen norm from mineral fertilizers was given to the nursery, and $100 \%$ of the annual amount of phosphorus fertilizers and $50 \%$ of potassium fertilizers were given to the main field before planting.

Due to the fact that the seedlings were cared for in the nursery for 25-30 days and fed with mineral fertilizers, and the main field was given $75 \%$ of the annual norm of nitrogen fertilizer.

In the planted areas, the first feeding was supplemented with $50 \%$ of the annual amount at the beginning of the rice accumulation period, the second feeding with $45 \%$ of the annual amount of nitrogen fertilizer remaining during the full accumulation period, and the remaining $50 \%$ of the potassium fertilizer.

In the direct seed control variant, the seeds were first soaked in water and then sown in water. For 1-2 days, 12-15 cm thick water was flooded, the sowing amount was sown at the rate of 5 million seeds per 1 ha, and the $12-15 \mathrm{~cm}$ water level was maintained for 6 days, then watering was stopped (Figure 5).
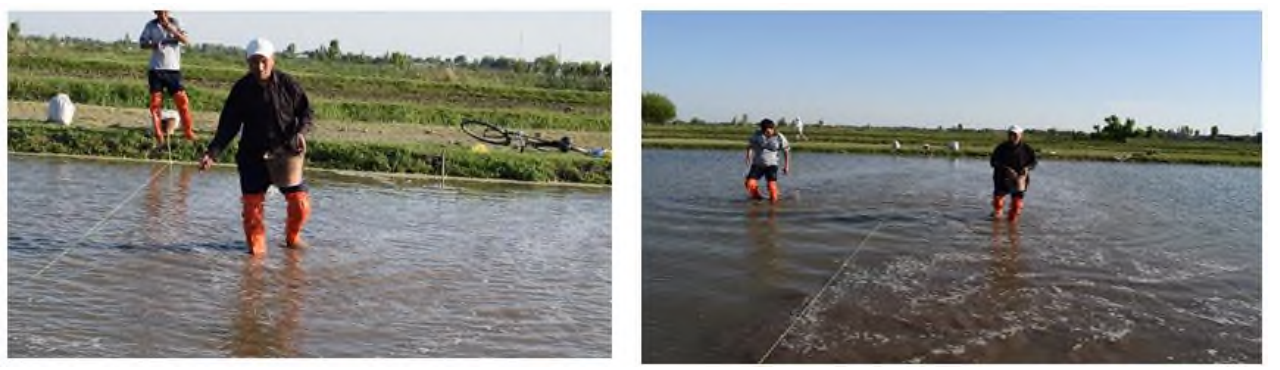

Fig. 5. Sowing rice seeds in a traditional way

After the grass sprouted, the checks were again filled with water to a thickness of 10$12 \mathrm{~cm}$. In the variant sown directly with seeds, when the rice had 3-4 leaves, the water in the borders was dried and treated with herbicide against weeds (1 to $25 \mathrm{ml}$ Guliver). The herbicide spray was sprayed on a hand-held hanging apparatus. On the second day after spraying the herbicide, a $15-18 \mathrm{~cm}$ thick layer of water was formed on the edges again. At the beginning of the accumulation period, the first fertilization was carried out, and after sowing the fertilizer, water was retained at a thickness of 5-8 cm. During the period of full collection, a second fertilization was carried out with the remaining $45 \%$ and after two to three days it was filled with $10-12 \mathrm{~cm}$ of water. This level was maintained until the end of the rice waxing period. In the rice planting options, no herbicide was sprayed and these costs were saved. 
After the rice wax had completely passed the ripening period, the water supply to the checks was completely stopped and the water on the surface of the checks was completely absorbed into the soil. When the rice was fully cooked, it was harvested by hand with a sickle and harvested by direct grinding.

\section{Results and discussion}

One of the main indicators that determine the yield in all crops is its biometric indicators. This is because the yield is determined by such indicators as the length of the pod, the number of grains in the pod, the weight of 1,000 grains $[1,6,8]$.

It was found that the cultivation of seedlings in different ways affected the main biometric indicators that determine the yield in accordance with the biology of rice plants and varieties as follows (Table 2).

Table 2. Influence of sowing methods on biometric indicators of rice

\begin{tabular}{|c|c|c|c|c|c|c|c|c|c|}
\hline \multirow[b]{2}{*}{$\#$} & \multirow[b]{2}{*}{ 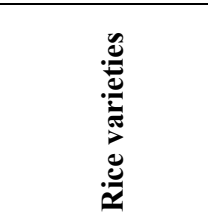 } & \multirow[b]{2}{*}{ 点 } & \multirow[b]{2}{*}{ 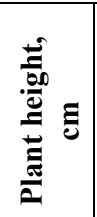 } & \multirow[b]{2}{*}{ 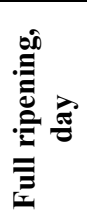 } & \multirow[b]{2}{*}{ 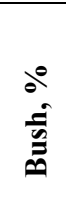 } & \multicolumn{3}{|c|}{ One pod } & \multirow[b]{2}{*}{ 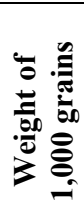 } \\
\hline & & & & & & 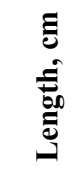 & Uُ & 先 & \\
\hline \multirow{2}{*}{1} & \multirow{2}{*}{ Taebaekbyeo } & Seed & 80.6 & 138 & 4.2 & 17.8 & 122 & 2.15 & 19.2 \\
\hline & & Plant & 78.2 & 106 & 7.8 & 17.2 & 128 & 2.57 & 20.1 \\
\hline \multirow{2}{*}{2} & \multirow{2}{*}{ Goami 4} & Seed & 82.1 & 146 & 3.7 & 14.2 & 74 & 1.35 & 17.6 \\
\hline & & Plant & 80.1 & 115 & 6.3 & 13.5 & 78 & 1.41 & 18.2 \\
\hline \multirow{2}{*}{3} & \multirow{2}{*}{ Jinbubyeo } & Seed & 85.6 & 129 & 3.1 & 15.0 & 71 & 1.62 & 22.9 \\
\hline & & Plant & 84.3 & 111 & 3.9 & 15.7 & 75 & 1.67 & 23.4 \\
\hline \multirow{2}{*}{4} & \multirow{2}{*}{ Heugjinjubyeo } & Seed & 79.7 & 125 & 3.5 & 15.5 & 81 & 1.29 & 17.1 \\
\hline & & Plant & 78.3 & 98 & 4.2 & 16.4 & 84 & 1.34 & 17.5 \\
\hline \multirow{2}{*}{5} & \multirow{2}{*}{ Dongjin } & Seed & 91.1 & 121 & 3.9 & 20.2 & 118 & 2.51 & 24.8 \\
\hline & & Plant & 96.7 & 97 & 5.4 & 19.5 & 121 & 2.59 & 25.6 \\
\hline \multirow{2}{*}{6} & \multirow{2}{*}{ Gongwang } & Seed & 105.6 & 115 & 3.2 & 17.8 & 107 & 2.85 & 28.1 \\
\hline & & Plant & 97.2 & 93 & 4.1 & 18.4 & 111 & 2.94 & 28.9 \\
\hline \multirow{2}{*}{7} & \multirow{2}{*}{ Tantana } & Seed & 123 & 122 & 2.6 & 20.0 & 110 & 3.1 & 31.8 \\
\hline & & Plant & 121 & 98 & 3.4 & 23.0 & 117 & 3.3 & 32.4 \\
\hline \multirow{2}{*}{8} & \multirow{2}{*}{ Tarona } & Seed & 122 & 131 & 2.2 & 22.0 & 104 & 3.3 & 33.1 \\
\hline & & Plant & 118 & 105 & 3.6 & 25.0 & 113 & 3.7 & 33.8 \\
\hline \multirow{2}{*}{9} & \multirow{2}{*}{ Lazurnyy } & Seed & 120 & 132 & 2.9 & 22.5 & 124 & 3.1 & 33.3 \\
\hline & & Plant & 118 & 106 & 4.2 & 23.2 & 131 & 3.5 & 34.0 \\
\hline \multirow{2}{*}{10} & \multirow{2}{*}{ Iskandar } & Seed & 123 & 121 & 2.2 & 21.8 & 138 & 4.3 & 33.0 \\
\hline & & Plant & 120 & 94 & 3.6 & 22.5 & 147 & 4.9 & 33.7 \\
\hline \multirow{2}{*}{11} & \multirow{2}{*}{ Sanam } & Seed & 102 & 95 & 2.7 & 17.4 & 113 & 3.4 & 30.2 \\
\hline & & Plant & 97 & 80 & 3.4 & 18.2 & 118 & 3.6 & 30.8 \\
\hline \multirow{2}{*}{12} & Guliakho & Seed & 117 & 110 & 2.2 & 17.9 & 88.9 & 2.1 & 32.2 \\
\hline & uuljaknon & Plant & 113 & 85 & 3.1 & 18.7 & 90.7 & 2.5 & 32.9 \\
\hline & & ECF 0.5 & & & & 4.1 & 3.8 & 3.2 & 2.5 \\
\hline
\end{tabular}

The most important processes that characterize plant ontogeny are growth and development. These two indicators are the result of all vital reactions in the body of plants, and these processes are inextricably linked. In this case, growth and development form a 
common whole and depend on physiological and biochemical processes in the plant body, plant nutrition through the roots and air, energy supply, in general, the sum of all processes involved in assimilation and dissimilation [5].

At the same time, the influence of meteorological, agrotechnical, soil, water and several other factors on the growth and development dynamics of the plant is also high.

In connection with the growth and development of the rice plant of these factors, a number of studies have been conducted by many of our local scientists at different times [8].

The study identified the impact of planting methods from seedlings and seeds of local and foreign rice varieties on plant growth and development (Figure 6).
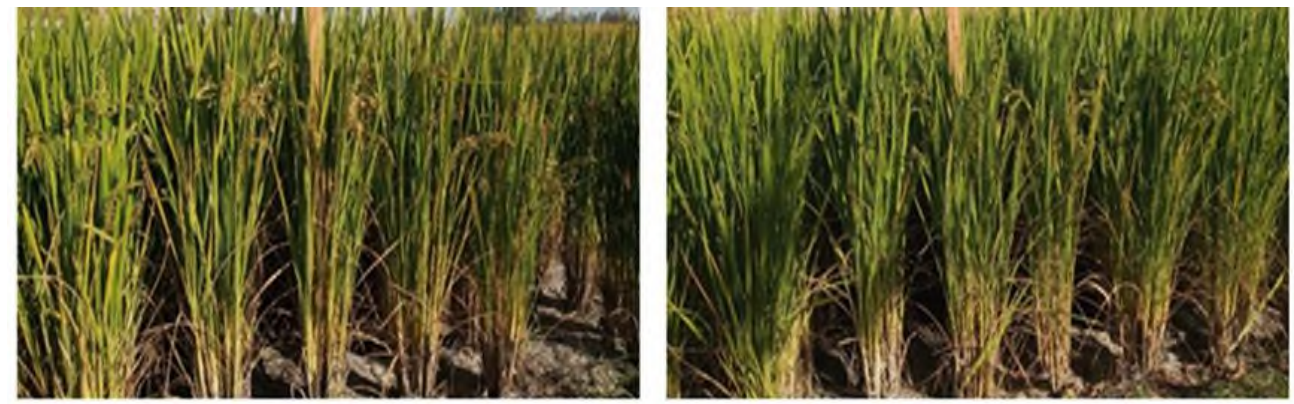

Fig. 6. Growth status of South Korean rice varieties

The height of local late varieties "Lazurnyy", "Tarona", "Tantana" was 120, 122 and $123 \mathrm{~cm}$ when sown from seeds, 118,120 and $121 \mathrm{~cm}$ when planted from seedlings, while the average height of "Iskandar" varieties was $120 \mathrm{~cm}, 123 \mathrm{~cm}, 117-97 \mathrm{~cm}$ when sowing seeds from early ripening varieties "Guljakhon" and "Sanam" and 113-97 cm when sowing seedlings.

South Korean rice varieties such as Jinbu, Taebaek, Goami, Heokjinju, Dongjin and Chokwang rose till $82.1 ; 85.6 ; 79.7 ; 97.1 ; 105.6 \mathrm{~cm}$ when sowed as aplant, but rose around $78.2 ; 80.1 ; 84.3 ; 78.3 ; 96.7 ; 97.2 \mathrm{~cm}$ when planted as a seed.

In both methods, local rice varieties are characterized by higher plant growth periods than foreign rice varieties. Local and foreign rice varieties are characterized by high indicators of grain yield in the variants planted in seedlings compared to the variants sown from seed. That is, when sown from the seeds of foreign rice varieties, the length of one row is $17.2 ; 13.5 ; 15.0 ; 15.5 ; 19.5$ and $17.8 \mathrm{~cm}$, the number of grains in the pod ranged 122 , $74,71,81,118$, and 107 , the weight of the grain in one pod was $2.15 ; 1.35 ; 1.62 ; 1.29 ; 2.51$ and 2.85 grams, respectively, and the weight of 1,000 grains was $19.2 ; 17.6 ; 22.9 ; 17.1$; 24.8 and 28.1 grams, respectively, when planted from rice seedlings $17.8 ; 14.2 ; 15.7 ; 16.4$; 20.2 and $18.4 \mathrm{~cm}$, respectively (Figure 7). 

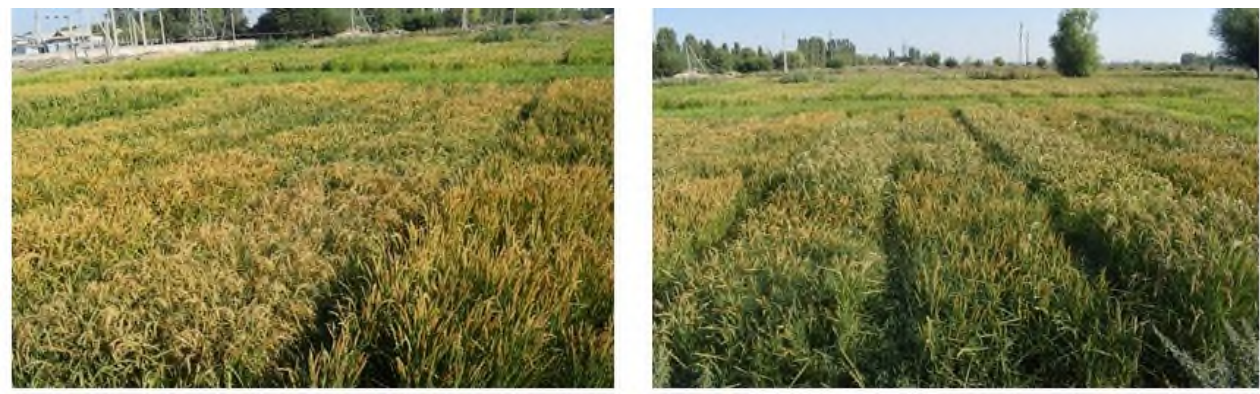

Fig. 7. Ripening status of rice

The data obtained confirm that, according to the results of the study on biometric indicators of rice, regardless of the method of cultivation, it was found that local rice varieties are higher than foreign rice varieties.

However, it should be noted that the degree of accumulation of foreign rice varieties was higher than that of domestic rice varieties and was distinguished by the fact that they were adapted to planting by mechanisms.

\section{Conclusion}

The impact of planting methods on the biometric performance of domestic and foreign rice varieties, as well as the selection of varieties for mechanized planting of rice seedlings can be summarized as follows.

Local and foreign varieties of rice are characterized by a high level of all indicators that determine the yield of rice grain in the variants sown from seedlings compared to the variants sown from seed.

In both methods, local rice varieties are characterized by higher plant growth periods than foreign rice varieties. According to the results of the study on biometric indicators, regardless of the method of sowing, it was observed that local rice varieties are higher than foreign rice varieties.

The degree of accumulation of foreign rice varieties (3.1-7.8\%) was higher (1.7-4.2\%) than that of local rice varieties (1.4-3.6\%) and was characterized by adaptability to planting by mechanisms.

It is necessary to develop the rice sector in the Republic of Uzbekistan, to move to a new system of rice cultivation by farmers and agro-clusters specializing in rice, that is, innovative preparation of rice seedlings used by advanced countries and mechanical planting.

In this way, planting and sowing work can be started 20-30 days before the preparation of the main rice fields, and the sowing of the latest rice varieties in different regions of the country will increase yields by $15-25 \%$ and reduce costs.

The technology of intensive cultivation of rice seedlings in special nurseries is the demand of the time and the most economical opportunity to provide rice clusters and farms with rice seedlings on a regular basis.

We would like to express our gratitude to the management and staff of Scientific Research Institute of Rice Culture and technical staff of the production experimental farm, as well as to the laboratory assistants who helped to determine the biometric parameters of the plant. In addition, We would like to express our sincere gratitude to our supervisor, Doctor of Agricultural Sciences, Professor R.SH. Tellyaev, who gave us valuable advice and support in conducting research. 


\section{References}

1. R. Tellyaev, M. Ergashev, B. Kodirov, Agro-business in Forum 3(158), 57-61 (2020)

2. Presidential Decree No. 3281 of the Republic of Uzbekistan on "Measures for the rational placement of agricultural crops in 2018 and the forecast volumes of agricultural production" on September 15, 2017

3. Presidential Decree No. 5742 of the Republic of Uzbekistan on "Measures for the efficient use of land and water resources in agriculture" on June 17, 2019

4. S. Ahmed, M. J. Alam, A. Hossain, A. K. M. Islam, T. H. Awan, W. Soufan, A. El Sabagh, Sustainability 13(1), 317 (2021)

5. R. K. Jha, P. K. Kalita, R. Jat, Paddy and Water Environment, 1-15 (2020)

6. R. Tellyaev, M. Ergashev, KH. Juraeva, Actual problems of modern science 5(108), 68-70 (2019)

7. Uzhydromet, Data on hydro-meteorological conditions of Tuyabugiz (2020)

8. E. Jumanov, S. Mahmudova, A. Egamnazarov, J. Agriculture of Uzbekistan 4, 19 (2003)

9. KH. Juraeva, R. Tillaev, Bulletin of Agrarian Sciences 4, 34-36 (2019)

10. R. R. Dzhamirze, N. V. Ostapenko, N. N. Chinchenko, In: 8th International Conference" Social Science and Humanity", 58-70 (2018)

11. L. Zhu, J. Sun, G. Wu, Y. Wang, H. Zhang, L. Wang, X. Qi, Journal of Cereal Science 82, 175-182 (2018)

12. M. Ergashev, J. Agriculture of Uzbekistan 2, 20 (2006).

13. G. O. Beisenova, R. Y. Eleshev, T. K. Vassilina, A. M. Shibikeeva, G. K. Vassilina, EurAsian Journal of BioSciences 13(2), 1527-1534 (2019) 